\title{
LAGRANGIAN MEASUREMENTS OF TURBULENT DISSIPATION OVER A SHALLOW TIDAL FLAT FROM PULSE COHERENT ACOUSTIC DOPPLER PROFILERS
}

\author{
Julia C. Mullarney ${ }^{1}$ and Stephen M. Henderson ${ }^{2}$
}

\begin{abstract}
We present high resolution ( $25 \mathrm{~mm}$ spatial, $8 \mathrm{~Hz}$ temporal) profiles of velocity measured over a shallow tidal flat using pulse-coherent Acoustic Doppler Profilers mounted on surface drifters. The use of Lagrangian measurements mitigated the problem of resolving velocity ambiguities, a problem which often limits the application of high-resolution pulse-coherent profilers. Turbulent dissipation rates were estimated from second-order structure functions of measured velocity. Drifters were advected towards, and subsequently trapped on, a convergent surface front which marked the edge of a freshwater plume. Measured dissipation rates increased as a drifter deployed within the plume approached the front. A drifter then propagated with and along the front as the fresh plume spread across the tidal flats. Near-surface turbulent dissipation measured at the front roughly matched a theoretical mean-shear-cubed relationship, whereas dissipation measured in the stratified plume behind the front was suppressed. After removal of estimates affected by surface waves, near-bed dissipation matched the velocity cubed relationship, although scatter was substantial. Dissipation rates appeared to be enhanced when the drifter propagated across small subtidal channels.
\end{abstract}

Keywords: drifters; turbulent dissipation; Lagrangian measurements; shallow flows; structure functions; pulse coherent profilers; tidal flats

\section{INTRODUCTION}

Freshwater plumes play a critical role in the nearshore transport and dispersal of nutrients, pollutants and sediments. However, in shallow environments such as tidal flats, it can be difficult to resolve smallscale flow features such as thin plumes, or the fronts that often form on the leading edges of spreading plumes. Traditional boat-sampling techniques do not measure close to the water surface, and many surface drifters have drafts exceeding $0.5 \mathrm{~m}$, precluding their deployment in very shallow water (Johnson et al. 2003; Austin and Atkinson 2004; Schmidt et al. 2003; MacMahan et al. 2009).

Exceptionally high spatial and temporal resolution velocity profiles, well-suited to resolving shallow flows, can be provided by 'pulse-coherent' Acoustic Doppler Profilers (ADPs). These instruments infer water velocity from the Doppler-induced phase shift between pairs of short acoustic pulses (Lhermitte and Serafin 1984; Lohrmann, Hackett and Røed 1990; Zedel et al. 1996). Unfortunately, application of these pulse-coherent systems is limited by the ability to uniquely resolve this phase shift between pulses; large phases are 'wrapped' onto the range $-\pi<$ phase $<\pi$, resulting in large errors in velocity measurements (Lohrmann and Nylund 2008). This wrapping leads to the constraint that velocities must not exceed a maximum value, with a smaller maximum required the longer the profile range. We present novel measurements from a pulse-coherent ADP mounted on a surface drifter in shallow (0.4 to $1 \mathrm{~m}$ deep) flows over a tidal flat in Skagit Bay, Washington. The drifter-mounted ADP moved with the fast surface flows, ensuring that the water velocities relative to the drifter were small and easily resolved by the pulse-coherent profiler. Hence, it was possible to overcome the difficulties associated with phase wrapping.

The field site, on the tidal flats of Skagit Bay, USA (Fig. 2), was characterized by shallow water depths (often $<1 \mathrm{~m}$ ) and thin (around $0.3 \mathrm{~m}$ thick) freshwater plumes. The leading edges of these plumes were marked by surface fronts which trapped drifters, foam and other flotsam. Initially, the fronts were trapped along the edge of a tidal channel by internal hydraulic control (Mullarney and Henderson 2011). However, as flood tide progressed and the flow over the flats became subcritical, the fronts departed from the channel edge and propagated across the flats against the incoming tidal flow (Fig. 2).

We estimate front-following rates of turbulent energy dissipation using data from the drifter-mounted ADP and the structure function method of Wiles et al. 2006. Similar dissipation estimates were recently obtained by Thomson 2012 using a wave following drifter with a draft of $1.25 \mathrm{~m}$. Whereas Thomson 2012 focuses on near-surface wave-injected turbulence in depths exceeding $1.25 \mathrm{~m}$, we study currents and dissipation from near the surface to the bed over shallow tidal flats (depths $\approx 0.3-0.9 \mathrm{~m}$ ).

\footnotetext{
${ }^{1}$ Department of Earth and Ocean Sciences, University of Waikato, Private Bag 3105, Hamilton, 3240, New Zealand

${ }^{2}$ School of the Environment, Washington State University Vancouver, 14204 NE Salmon Creek, Vancouver, WA, 98686, USA
} 


\section{DATA COLLECTION AND ANALYSIS \\ Drifter design}

A novel drifter design was developed, with a low draft $(\sim 0.06 \mathrm{~m})$ suitable for use in very shallow flows, and with an attachment point for mounting a Nortek Aquadopp Acoustic Doppler Profiler (ADP) (Mullarney and Henderson in prep.). The drifters were close to neutrally buoyant, and extended about $10 \mathrm{~mm}$ above the water surface (Fig. 1). A GPS unit (i-Blue PhotoMate 887 mini logger) was attached to the top side of the drifter and enclosed in a waterproof box. The GPS sampled at $1 \mathrm{~Hz}$, with a horizontal positioning accuracy of around $3 \mathrm{~m}$. Downward-looking Acoustic Doppler Profilers ( $2 \mathrm{MHz}$ Nortek Aquadopps) were attached to drifters with transducers situated approximately $0.16 \mathrm{~m}$ below the surface (in all results presented below, the depth of velocity measurements has been calculated by adding $0.16 \mathrm{~m}$ to the range beneath the ADP). High resolution ( $8 \mathrm{~Hz}$ temporal and $0.0276 \mathrm{~m}$ along-beam resolution, corresponding to $0.025 \mathrm{~m}$ vertical resolution) measurements of velocity were recorded $0.063-0.74 \mathrm{~m}$ beneath the instrument along the three acoustic beams over bursts of $512 \mathrm{~s}$ with an interval between bursts of $3 \mathrm{~s}$.

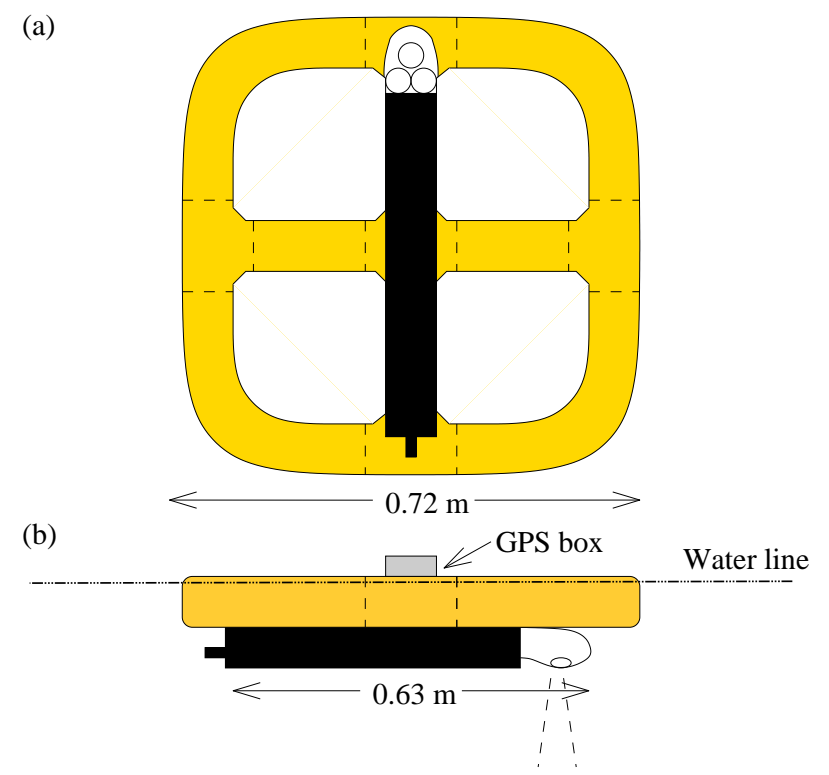

Figure 1: (a) Plan view (from underneath) of drifter with Nortek Aquadopp Acoustic Doppler Profiler attached. (b) Side view of drifter showing approximate location of water line. The transducers were situated at approximately $0.16 \mathrm{~m}$ below the water line.

\section{Field Site and flow dynamics}

Drifters were deployed during August 2009 in Skagit Bay in northern Puget Sound, Washington State, USA (Fig. 2). This meso-tidal bay is characterised by broad sandy tidal flats, incised by a braided network of shallow subtidal channels. These channels were continuously fed with freshwater from the north branch of the Skagit River. Many observations presented here were collected near the easternmost distributary channel, which was around $0.7 \mathrm{~m}$ deep when the flats were exposed at low tides. Drifters were deployed shortly after the incoming tide flooded the tidal flats, with water approaching the channel obliquely (dominant flow direction from around $200^{\circ}$ ). Maximum flood tide velocities in the channel reached around $0.5 \mathrm{~m} \mathrm{~s}^{-1}$.

Wind speeds and directions were measured every minute by a Hobo Onset weather station located $4.2 \mathrm{~m}$ above the tidal flats (white circle, Fig. $2 \mathrm{~b}$ ). During the drifter deployments, a light afternoon sea breeze generated small waves (Henderson and Mullarney 2012).

A drifters was initially released on the tidal flats shortly after the onset of flood tide (\#1, Fig. 2b) 
and was advected to a surface front marking the edge of fresh plume (\#2). A convergent surface flow then held the drifter on the front, which extended roughly along the western edge of the tidal channel (Mullarney and Henderson 2011 explain the formation of the front along the channel edge). The drifter travelled along the channel-edge front (\#3), with freshwater to the east, before becoming entangled in salt marsh vegetation at the edge of the flats (\#4), at which point the drifter was recovered. At this stage the front left the channel edge and starting propagating westward, forming the leading edge of a spreading freshwater plume (Mullarney and Henderson 2011 explain the timing of the departure of the front from the channel-edge). The drifter was then redeployed in the freshwater plume, just of east of the front, near the channel edge (\#5). The drifter was then carried to the front by convergent surface currents, joining the front about 15 minutes after release, and then was advected with the front as it propagated westwards across the tidal flats (\#6). The plume was only around $0.3 \mathrm{~m}$ thick, yet retained its strength as it propagated more than a kilometer across the flooded flats.

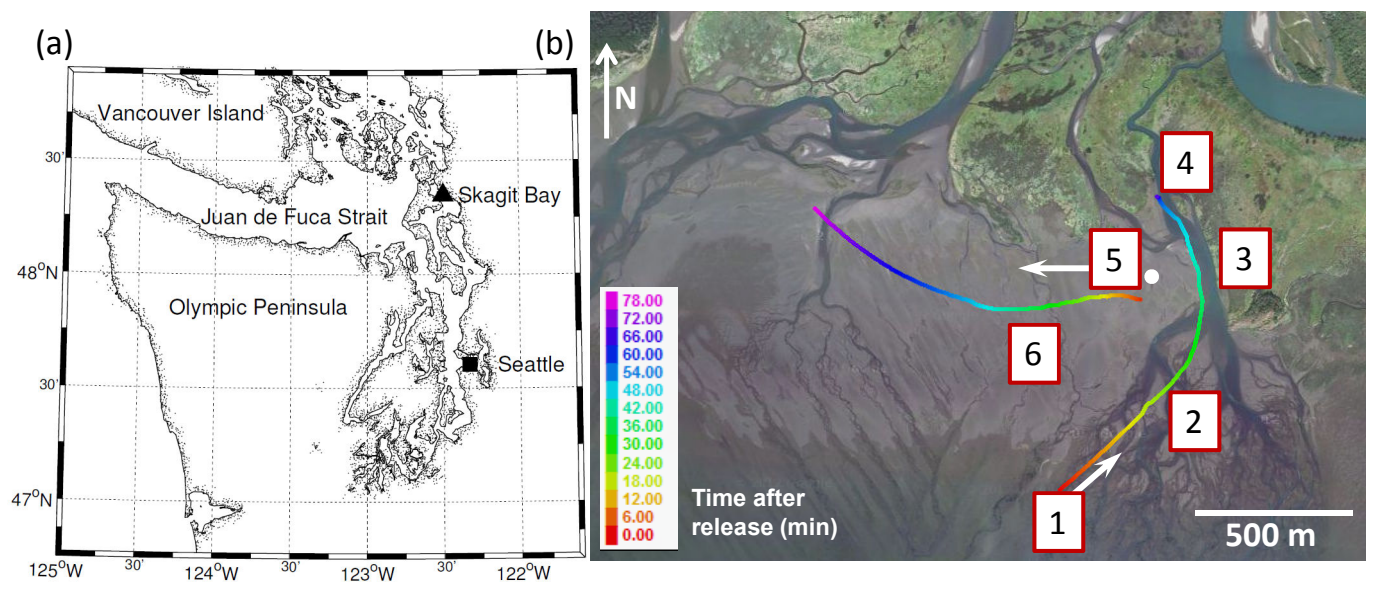

Figure 2: (a) Coastline of Puget Sound, Washington, USA showing the location of Skagit Bay. (b) Google Earth Image with tracks of a single drifter from $19^{\text {th }}$ August 2009 superimposed. Key events are labelled: 1 - drifter release, 2 - drifter trapped in front, 3 -front (and drifter) held along channel edge by hydraulic control, 4 - drifter collected, 5 - drifter re-released and 6 - drifter has rejoined front and is advected across tidal flats at the head of a thin fresh plume. See text for more details. The white circle shows the location of the weather station.

\section{Data processing}

Post-processing of pulse-coherent ADP data removed bins with low $\left(<c_{c r i t}\right)$ correlations. Two critical correlation values $\left(c_{c r i t}=50 \%\right.$ or $\left.70 \%\right)$ were used to examine the sensitivity of the results to the chosen correlation threshold. To obtain velocities relative to Earth coordinates, along-beam velocities were rotated into East-North-Up (ENU) components and corrected for the motion of the drifter. In shallow regions where the ADP profile reached the bed (as identified in the measured acoustic backscatter intensity), the relative motion of the drifter was calculated by removing each component of apparent bed velocity measured by the moving ADP. Horizontal velocity components were smoothed with a 20 -s moving average. Vertical components were dominated by wave-induced fluctuations, with relatively small mean values. To retain wave-induced motions, vertical velocities were not smoothed. In deeper regions where the ADP profile did not reach the bed, the horizontal drifter motion was calculated by differencing the GPS positions and and smoothing each velocity component using a 60s moving average. In these cases the vertical velocities could not be resolved. Good agreement was found between the two methods of removing drifter motion (Mullarney and Henderson in prep.).

Following Wiles et al. 2006, the turbulent kinetic energy (TKE) dissipation rate $\epsilon_{i}$ was estimated along 
beam $i$ using the second order structure function

$$
D(z, r)=\overline{\left[v^{\prime}(z-r / 2)-v^{\prime}(z+r / 2)\right]^{2}}
$$

where $v^{\prime}(z)$ is the along-beam velocity fluctuation at along-beam location $z$, and the overbar denotes a time average. From Kolmogorov's theory, for scales $r$ within the inertial subrange,

$$
D(z, r) \sim C_{v}^{2} \epsilon^{2 / 3} r^{2 / 3}
$$

where $C_{v}^{2}=2.1$ is a constant (Monin and Yaglom 1975, Section 21.4). The relationship

$$
D(z, r)=N+A r^{2 / 3}
$$

was fitted by linear regression, using all $0<r<r_{\text {max }}$, yielding the estimate $\epsilon=A^{3 / 2} C_{v}^{-3}$. Here, the constant $r_{\text {max }}$ is the chosen maximum separation distance, and $N$ is a fitted parameter related to the ADP noise variance, which is assumed independent of $r$.

Estimates for turbulent dissipation rates $\epsilon_{i}$ were made over a rolling window of 512 data points $(64 \mathrm{~s})$, with results discarded whenever $<70 \%$ of data exceeded the critical correlation threshold $c_{c r i t}$. The assumed inertial subrange theory applies only for $r$ small compared with both the Ozmidov scale and the distance to the boundary. We investigated sensitivity to $r_{\text {max }}$, with results presented below. Estimates of $\epsilon_{i}$ for a given $r_{\max }$ were retained only if the correlation threshold criterion was met by all bins for which $r<r_{\text {max }}$. Fits where $A<0$ were removed.

Structure functions, and associated dissipation estimates, depend only on velocity differences between range bins, and not on absolute velocities. Therefore, range-independent velocity offsets resulting from drifter motions did not affect dissipation estimates. To investigate the influence of depth-dependent wave motions, two different estimates of $\epsilon$ were calculated. The first estimate $\left(\epsilon_{i}\right)$ used raw velocities, whereas the second estimate $\left(\epsilon_{i}^{*}\right)$ used velocities that had been filtered to remove part of the wave motion. Partial removal of wave motions was achieved by subtracting the component of the velocity that was coherent with the measured pressure. This method will not remove all of the wave motion, because directional spreading reduces velocity-pressure correlations, because slow drifter rotation caused apparent variations in wave angles, and because wave-induced drifter motion influenced the measured pressure time series. We removed from the data set cases when

$$
\left|\frac{\epsilon_{i}^{*}-\epsilon_{i}}{\epsilon_{i}^{*}+\epsilon_{i}}\right|>0.25 .
$$

This approach removed the clearest cases of wave contamination ( $<3 \%$ of data per beam), but is unlikely to remove all wave-affected cases.

Within the $64 \mathrm{~s}$ windowing time, drifters typically travelled $15-25 \mathrm{~m}$. Water velocities and drifter speeds often reached $0.3 \mathrm{~m} \mathrm{~s}^{-1}$ when measured relative to the seabed. The spatial separation between beams was small (relative to the propagation distances) and hence $\epsilon$ estimates did not vary significantly between the three beams. Therefore, for each time and depth, $\epsilon$ was taken as the mean value over all beams for which epsilon estimates passed the quality control criteria.

Owing to the use of Lagrangian drifters, less than $1 \%$ of measured water velocities reached $0.3 \mathrm{~m} s^{-1}$ relative to the ADP. In addition to minimizing wrapping problems this reduction in velocities relative to the ASP may be important for resolution of small turbulent eddies. Since each recorded velocity is an average over $0.125 \mathrm{~s}$, eddies with spatial scales less than about $u_{r e l} \times 0.125 \mathrm{~s}$ were unresolved, where $u_{r e l}$ is the velocity relative to the ADP. If instruments had been stationary $u_{r e l}$ would often have reached $0.3 \mathrm{~m} \mathrm{~s}^{-1}$, so $\sim 40 \mathrm{~mm}$ eddies would have been suppressed in the ADP data, likely leading to significant errors in the structure function estimates. Owing to the use of Lagrangian drifters, $u_{r e l}$ was usually small, yielding better-resolved structure functions.

Sample structure function fits for a single beam are shown in Fig. 3 from the ADP during the second drifter release (\#5, 6, Fig. 2b). In this case, dissipation was enhanced near the bed and data near the surface did not meet the quality control criteria. 

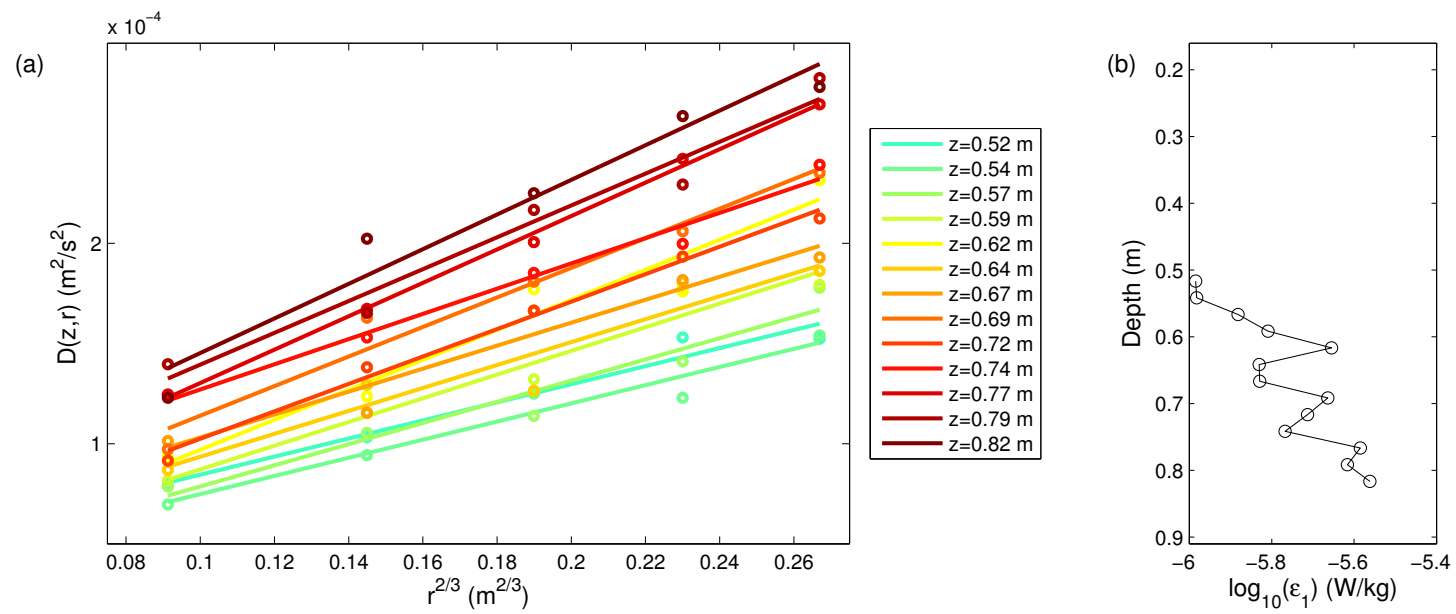

Figure 3: (a) Example structure functions (circles) and associated fits (lines) to Eq. 3 for a single beam from an ADP on the drifter propagating westwards across the flats (green line, Fig. $\mathbf{2 b}$ ) at $\mathbf{t} \approx \mathbf{5 1}$ min after release. (b) profile of $\epsilon$ against depth for the fits shown in (a).

\section{RESULTS}

Raw data from a single beam during the first drifter release (\#1-4, Fig. 2) are shown in Fig. 4. Enhanced backscatter was observed at $t=40-60 \mathrm{~min}$ after drifter release (Fig. 4a), during which time the drifter travelled along a front which was trapped near the channel edge (\#3, Fig. 2b). Correlations indicated generally high quality data, with the exception of a $\sim 5 \mathrm{~cm}$ high band of low correlations. This low correlation band was caused by interference between the bottom reflection of one acoustic pulse and the water column backscatter of a succeeding pulse. Consequently, the elevation of the low correlation band followed the bathymetry. Raw along-beam velocities relative to the instrument were low, particularly closer to the instrument, and very little phase wrapping is visible (Fig. 4c).

Converting raw velocities (e.g. Fig. 4c) into ENU coordinates and correcting for drifter motion reveals times of sheared flow (e.g. $t=34-47 \mathrm{~min}$, Fig. 5a,b) and a time of downwelling at $t \approx 38 \mathrm{~min}$ (Fig. 5c) when the drifter reached the channel edge, where the incoming seawater cascaded down into the channel (Mullarney and Henderson 2011). A change in flow direction at $t=50$ min coincided with a sudden change in wind direction (Fig. 7e).

Estimated TKE dissipation rates for the second drifter release did not exhibit large sensitivity to the choice of correlation threshold $c_{\text {crit }}$ or maximum structure function separation distance $r_{\max }$ (Fig. 6). As expected, more data passed the quality control criteria for the lower correlation threshold and smaller maximum separation distances. A near-surface region of intense TKE dissipation around $t=38 \mathrm{~min}$ (Fig. 6a) was not resolved when using a larger maximum separation distance or higher correlation threshold. As longer structure-function separation distances were used in dissipation estimates, estimated dissipation rates declined. This departure from inertial subrange scaling at larger maximum separation distances cannot be explained by wave contamination, which would cause dissipation estimates to increase with separation distance, but instead likely indicates suppression of relatively large-scale turbulence. Such suppression might result from stratification, or from the presence of surface and bottom boundaries. Hereafter, TKE dissipation rates are shown for a correlation threshold of $c_{c r i t}=50 \%$ and a maximum separation distance $r_{\text {max }}=110 \mathrm{~mm}$ (4 rangebins).

Estimated TKE dissipation rates (Fig. 7a,b) and backscatters (Fig. 7c,d) were generally higher during the first drifter release than during the second. The highest dissipation rates occurred during the first release as the drifter propagated along the edge of the channel at $t=35-50 \mathrm{~min}$. Intense shear has previously been observed at this location, as seawater from the tidal flats flows under the fresh surface 
(a)
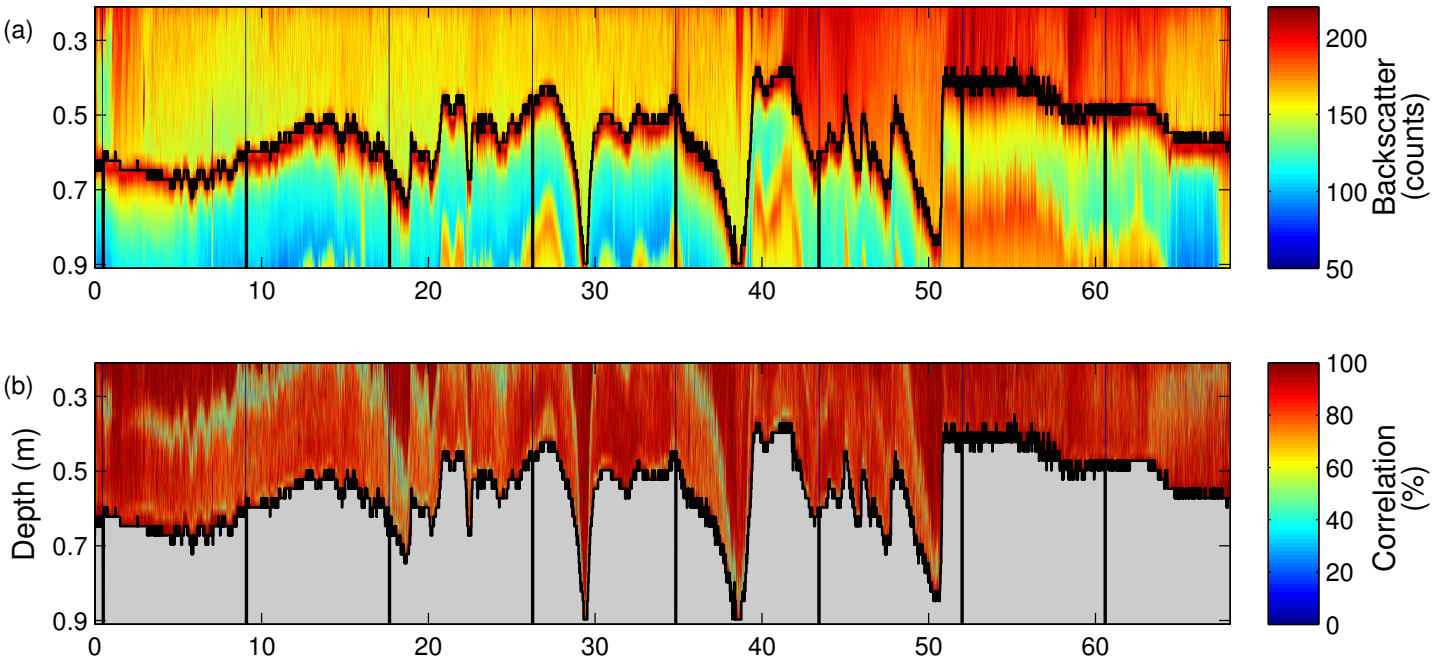

(c)

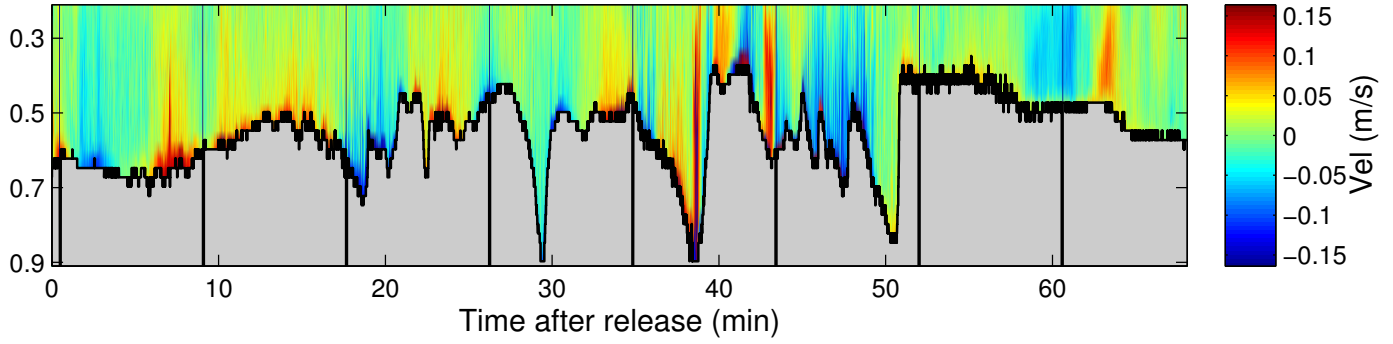

Figure 4: Data from a single ADP beam, from first drifter release (\#1-4, Fig. 2a). (a) Backscatter, (b) correlation, (c) along-beam velocity. The black line shows the location of the bed. Vertical black lines show gaps between bursts.

plume and cascades down into the channel (Mullarney and Henderson 2011).

During the second release, high levels of backscatter, often accompanied by intensified turbulent dissipation were observed to briefly penetrate throughout the depth of the water column (marked by black and red arrows, Fig. 7b,d). For simplicity, an 'event' was noted if backscatter at depth $0.77 \mathrm{~m}$ exceeded 160 counts for 5 consecutive data points. The locations of these events are marked on a Google Earth Image from 1 May 2009. Large scale shifts in the channel features on the tidal flat typically did not occur over timescales of months, so this image is representative of the bathymetric features during the deployments (19 August 2009). The enhancement of backscatter and TKE dissipation rate at $t=17-$ 18, 21, 23, 26, 29, 35 and 74 min (black arrows, Fig. 7b,d) coincided with times when the drifter crossed small subtidal channels. The remaining high backscatter and TKE dissipation events at $t=43,46$ and 60 min (red arrows, Fig. 7b,d) were not associated with clear channel crossings.

During the first release, winds changed direction and strengthened after 50 minutes (Fig. 7e). During the second release, winds changed direction and weakened after $40-50$ minutes (Fig. 7f). The pitch and roll variances measured by the ADP at frequencies $>0.5 \mathrm{~Hz}$ (Fig. $7 \mathrm{~g}, \mathrm{~h}$ ) gives a qualitative indication of occasions when wind-waves were present. Waves were likely largest during the first 40 minutes of release 2 (Fig. 7h), when winds were relatively strong (Fig. 7f). The relatively strong winds encountered after 50 minutes during release 1 were not associated with high measured wave activity (compare scales on Fig. $7 \mathrm{~g}, \mathrm{~h}$ ), likely owing to the sheltering effect of a salt marsh $<100 \mathrm{~m}$ to the north (Fig $2 \mathrm{~b}$ ). 
(a)
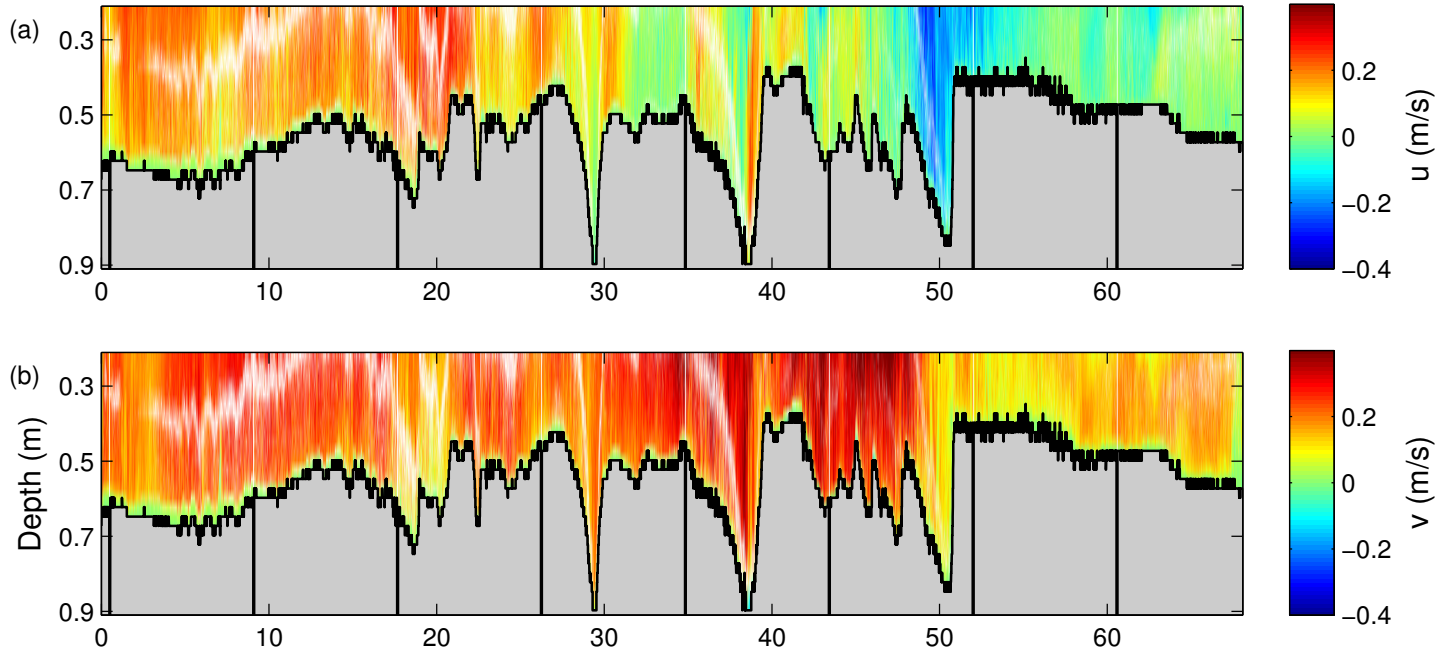

(c)

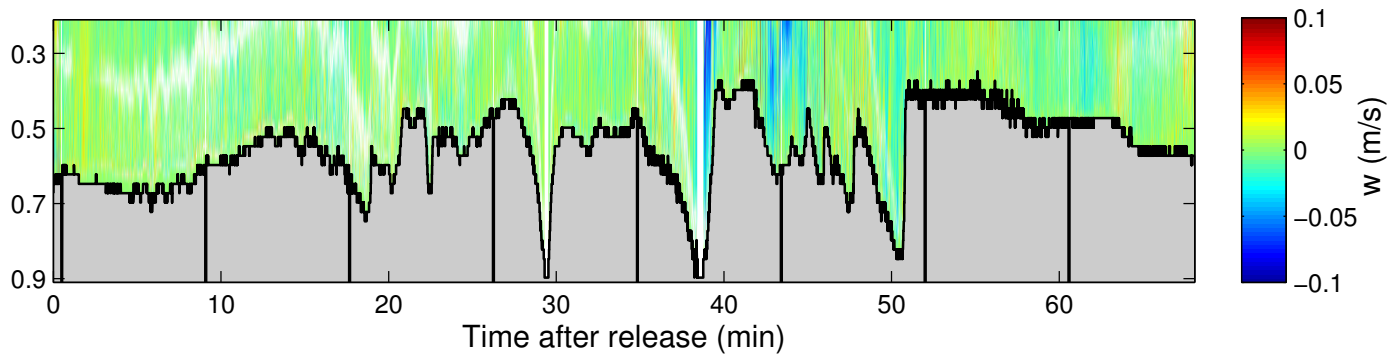

Figure 5: Eastward (a), northward (b), and upward (c) velocities from first drifter release (c.f. Fig. 4). The black line shows the location of the bed. Vertical black lines show gaps between bursts. White regions indicate bad data $\left(c_{\mathrm{crit}}<\mathbf{5 0} \%\right)$ from one or more beams

In many cases the TKE dissipation rate $\epsilon$ scales with $u^{3} / l$, where $u$ and $l$ are mean-flow velocity and length scales. In the case of a drifter trapped on a surface front, where much turbulent energy production results from the near-surface shear $|\partial \mathbf{u} / \partial z|=\left[(\partial u / \partial z)^{2}+(\partial v / \partial z)^{2}\right]^{1 / 2}$, a more appropriate scaling may be $\epsilon=l^{2}|\partial \mathbf{u} / \partial z|^{3}$. We tested the ability of this scaling to predict observed near-surface dissipation. At depth $z=0.35 \mathrm{~m}$, the shear $|\partial \mathbf{u} / \partial z| \approx\left(\Delta u^{2}+\Delta v^{2}\right)^{1 / 2} / \Delta z$ was estimated by differencing 64-s-averaged velocities measured at $z=0.3$ and $0.4 \mathrm{~m}$. When all data from drifter deployment 2 are considered, no clear relationship can be seen between $\epsilon$ at $z=0.35 \mathrm{~m}$ and $|\partial \mathbf{u} / \partial z|$ (all points, dashed line fit, Fig. 9a). However, when cases where the drifter was trapped on the plume front ( $t>15 \mathrm{~min}$, red squares) are separated from cases where the drifter was in the stratified plume behind the front $(t<15 \mathrm{~min}$, blue circles), a clear pattern emerges. The TKE dissipation rate at the front scaled as $\epsilon=\alpha|\partial \mathbf{u} / \partial z|^{\gamma}$, where $\alpha=4.6 \times 10^{-5} \mathrm{~m}^{2}$ and the fitted $\gamma=3.3$ was close to the theoretical value $\gamma=3$ (Fig. 9b). Assuming a mixing-length model and a production-dissipation balance yields a very small mixing length $l=\alpha^{1 / 2} \approx 7 \times 10^{-3} \mathrm{~m}$. The low $l$ value can not be explained by wave-induced errors in $\epsilon$ estimates, or by wave-injected turbulence, both of which would lead to over-estimation, but might instead indicate departures from the mixing-length model or the assumed production-dissipation balance at the plume front. Behind the front, TKE dissipation rates dropped below the $\epsilon=\alpha|\partial \mathbf{u} / \partial z|^{\gamma}$ relationship observed at the front, possibly owing to suppression of mixing by stratification, as is often observed behind the head of gravity currents (Simpson 1997).

Near-bed dissipation rates (taken $0.2 \mathrm{~m}$ above the bed or $0.2 \mathrm{~m}$ above the bottom rangebin if no bed was discerned from the backscatter trace) did not show a clear dependence on near bed velocity (all data, 

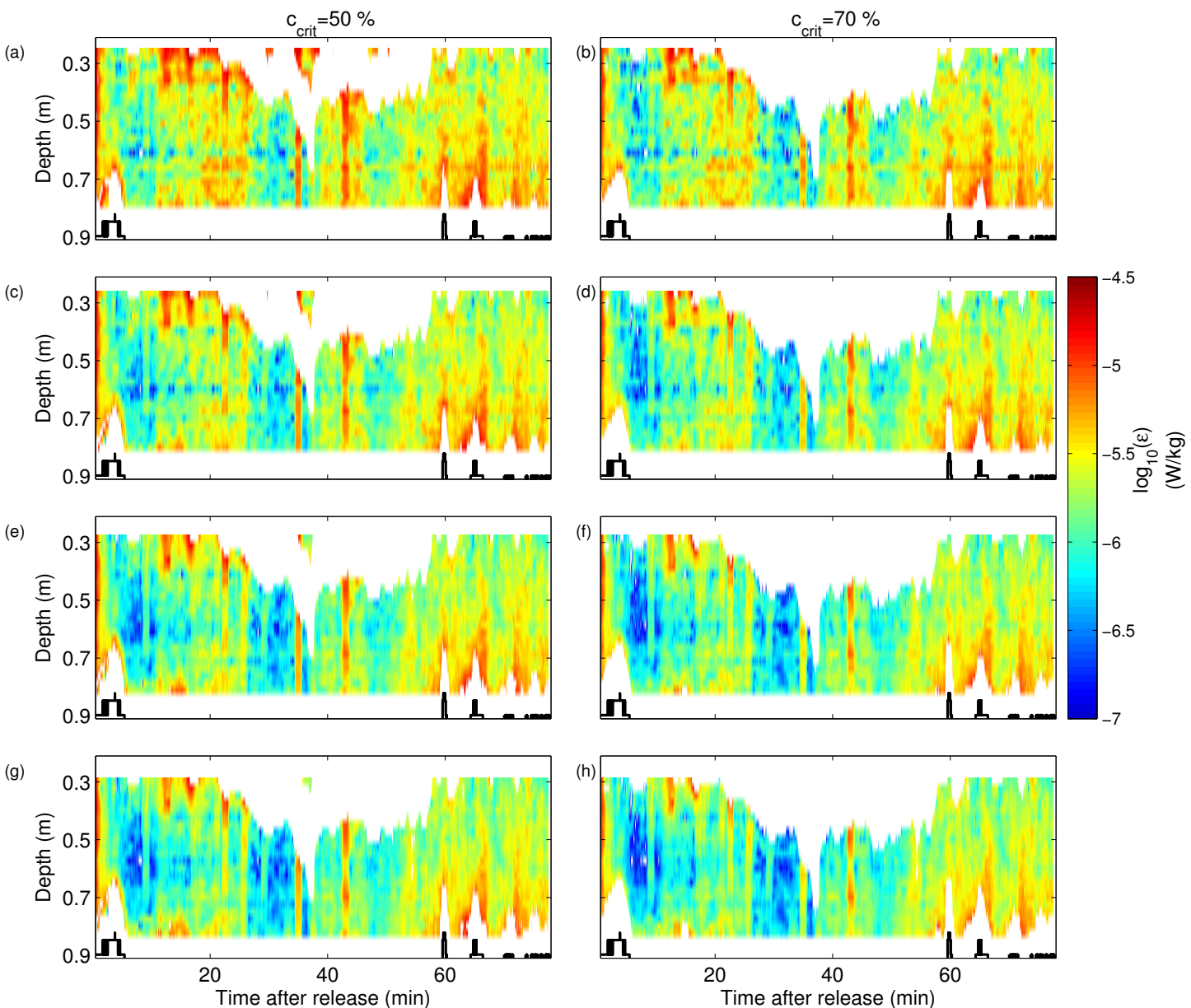

Figure 6: Turbulent dissipation rate (logarithmic scale) from the second drifter release (\# 5,6, Fig. 2b) showing sensitivity to critical correlation threshold $c_{\text {crit }}$ and maximum separation distance $r_{\max }$. Left column $c_{\text {crit }}=\mathbf{5 0} \%$, right column $c_{\text {crit }}=\mathbf{7 0} \%$. Separation distances of (a) and (b) $83 \mathrm{~mm}$ (3 rangebins), (c) and (d) $110 \mathrm{~mm}$ (4 rangebins), (e) and (f) $138 \mathrm{~mm}$ (5 rangebins), and (g) and (h) $166 \mathrm{~mm}$ (6 rangebins). The black line shows the location of the bed when visible in the backscatter trace.

Fig. 10a). Waves can increase near-bed stress and effective bottom roughness, possibly confounding simple relationships between dissipation and mean currents (Grant and Madsen 1986). The enhanced TKE dissipation rates observed as the drifter propagated above channels may also obscure the scaling relationships. Indeed, removing times of higher wave energy $\left(\sigma_{p}^{2}+\sigma_{r}^{2}>0.031^{\circ 2}\right)$ and times when the drifter was above or close to the edge of a subtidal channel (indicated by near-bed backscatter $>140$ counts) does yield a weak correlation between dissipation and velocity (red squares, Fig. 10). For the data removal criteria given above, the bin averaged data (bin width $0.01 \mathrm{~m} \mathrm{~s}^{-1}$ ) show a dependence of dissipation rate on near-bed velocity of $\epsilon \sim u^{3.3}$, not inconsistent with the theoretical cubed value. However, the fitted power law was sensitive to the arbitrary cut-off for wave removal (e.g. choosing $\sigma_{p}^{2}+\sigma_{r}^{2}>0.028^{\circ 2}$ yielded $\left.\epsilon \propto|u|^{4.3}\right)$. 

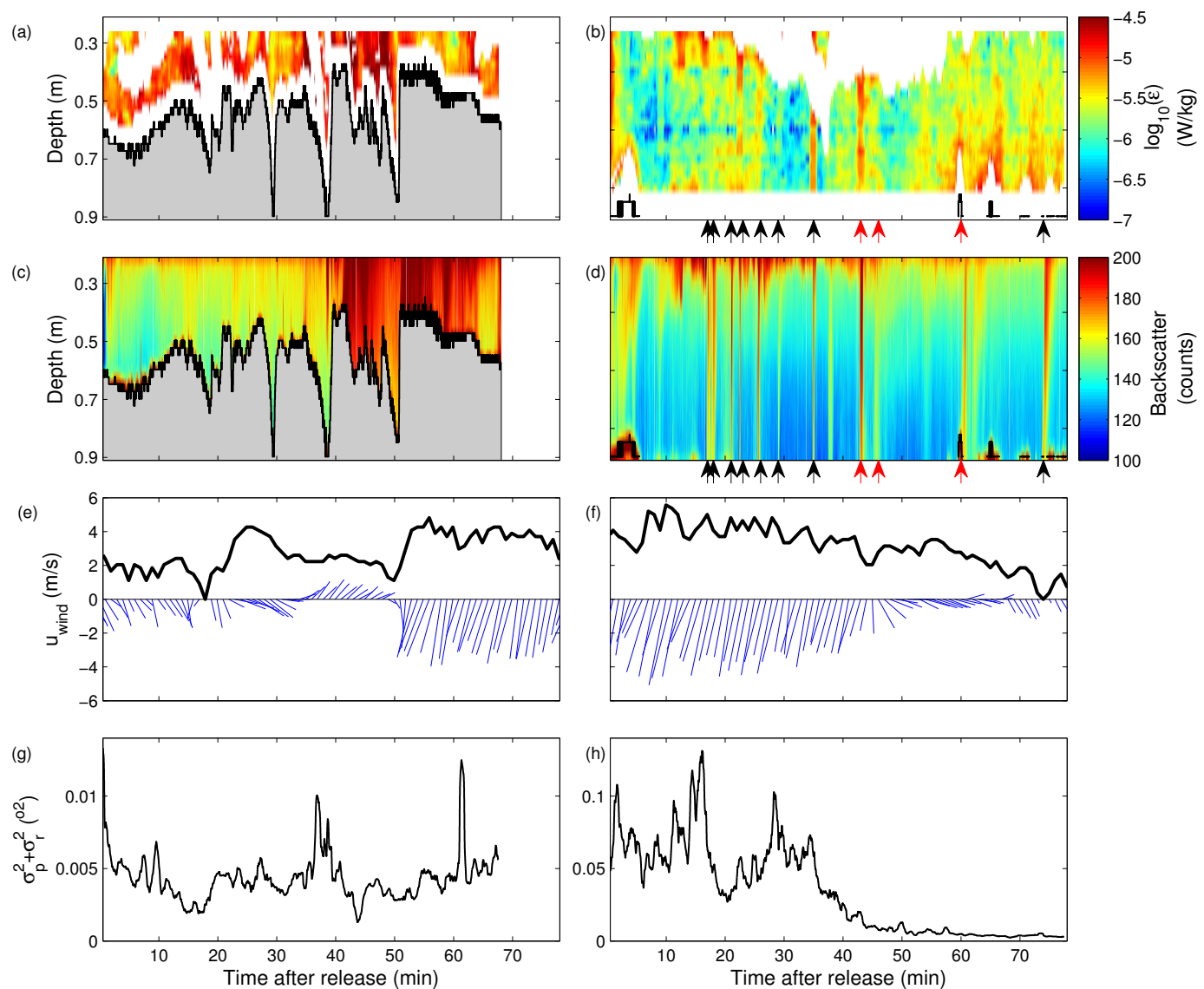

Figure 7: Comparison of first (left panels) and second (right panels) drifter releases. (a) and (b) TKE dissipation rate using a $50 \%$ correlation threshold and separation distance of $110 \mathrm{~mm}$ (4 rangebins). (c) and (d) smoothed backscatter (mean over three beams). The black line indicates the bottom. Arrows indicate high backscatter events, with the events associated with clear channel crossings shown in black. (e) and (f) measured wind vectors (blue) and speeds (black). (g) and (h) variance $\left(\sigma_{\mathrm{p}}^{2}+\sigma_{\mathrm{r}}^{2}\right)$ of ADP pitch and roll measurements for frequencies $>0.5 \mathrm{~Hz}$.

\section{CONCLUSIONS}

We estimated TKE dissipation rates $0.27-0.87 \mathrm{~m}$ below the water surface using a pulse-coherent Acoustic Doppler Profiler mounted on a low-draft surface drifter. The drifter was deployed over a shallow tidal flat, and was quickly carried to a convergent surface front which marked the boundary between a fresh plume and surrounding salt water. Most ADP velocity data was of high quality, with the exception of thin $(\sim 0.05 \mathrm{~m})$ bands of low correlation caused by pulse-to-pulse interference.

Near-surface TKE dissipation rates were enhanced near the front at the plume's leading edge. Once the drifter had become trapped in the front, dissipation rates were found to agree well with a theoretical shear-cubed scaling.

Wave motion was partially removed prior to calculation of dissipation rates. Anomalously rapid increases in estimated structure functions with maximum separation distance, which would be expected for wave-contaminated data, were not observed. However, larger dissipation rates were observed near the bed in times of higher wave energy, suggesting that waves generated enhanced near-bed turbulence. 


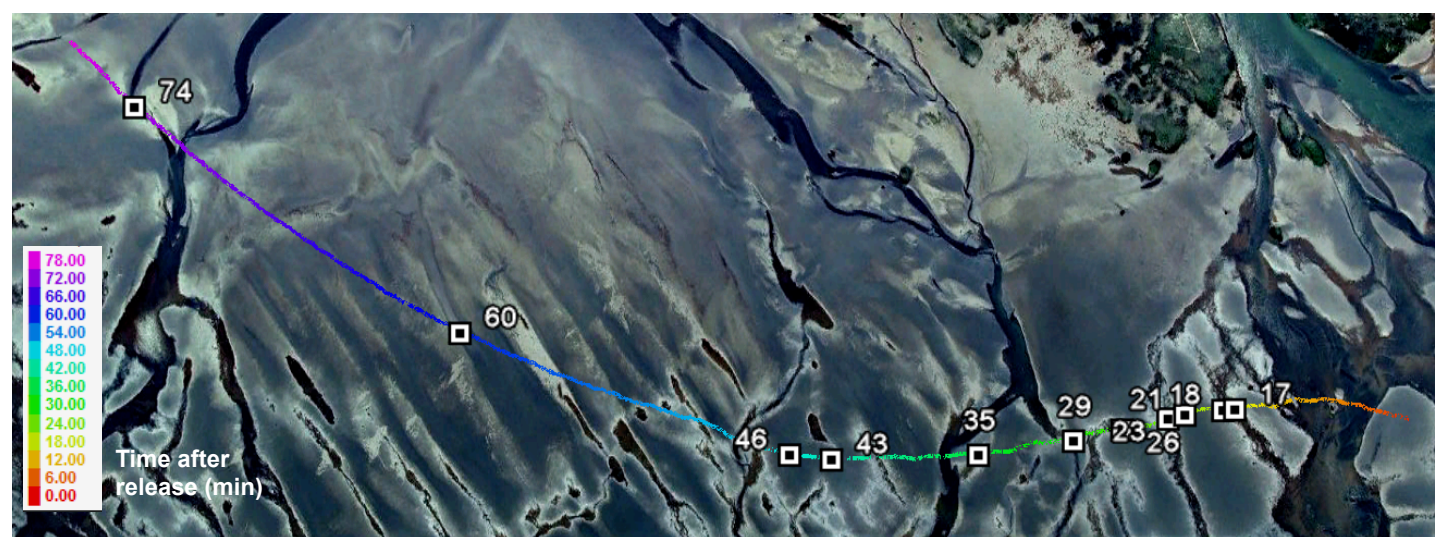

Figure 8: Drifter track from second release plotted on a Google Earth image taken 1 May 2009. Colours indicate the time after release. Squares indicate events with high backscatter, numbers give the associated time after release in minutes.
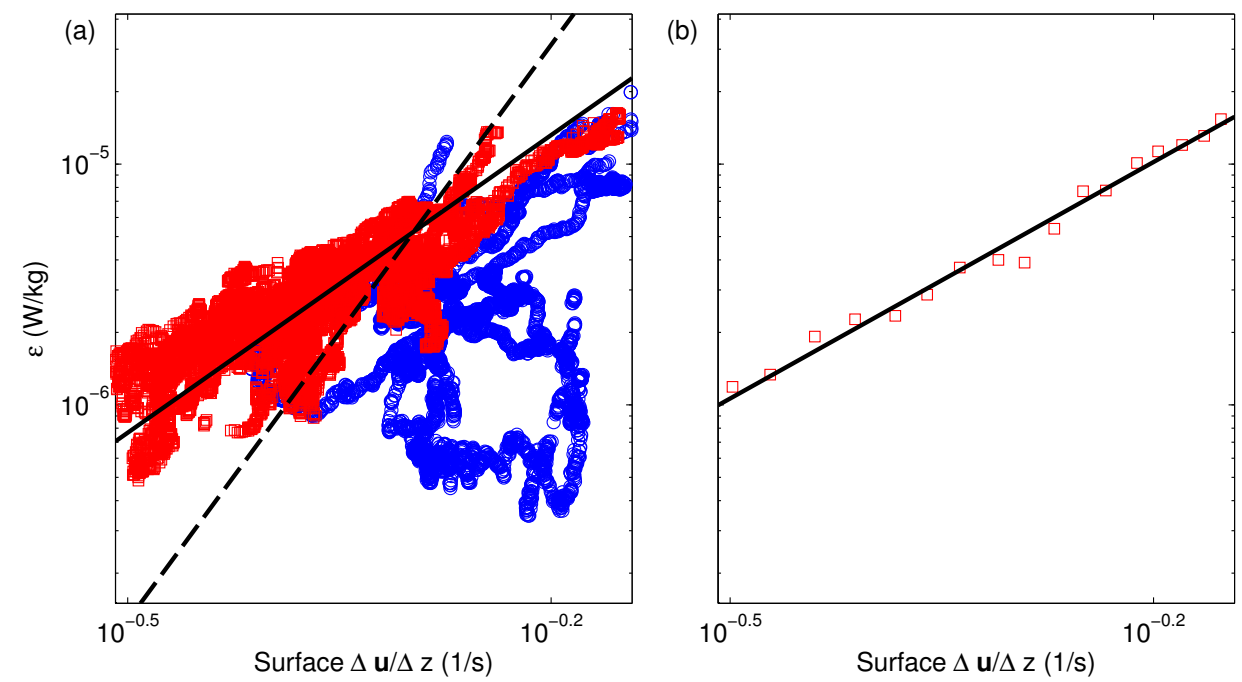

Figure 9: TKE dissipation rate at depth $\mathrm{z}=\mathbf{0 . 3 5} \mathrm{m}$ versus near-surface shear $\left(\sqrt{(\Delta \mathrm{u})^{2}+(\Delta \mathrm{v})^{2}} / \Delta \mathrm{z}\right.$ between $\mathrm{z}=\mathbf{0 . 3}$ and $0.4 \mathrm{~m}$ ). (a) Raw data recorded before (blue circles) and after (red squares) the drifter had rejoined the surface front $(t>15 \mathrm{~min}$ red squares). The lines show fits to all data (dashed line, slope $=$ 8.0) and data with drifter on front (solid line, slope = 4.1). (b) Data from after the drifter had rejoined the front divided into bins of shear $0.025 \mathrm{~s}^{-1}$. Squares show mean for each bin and the slope of the fit is 3.3 . In all cases, the lines show the slope of the first EOF.

In times of low wave energy, after enhanced dissipation events associated with channel crossings had been removed, the dependence of near-bed TKE dissipation rates on near-bed velocity was close to the theoretical cubed-relationship, although there was substantial scatter around the measurements.

\section{ACKNOWLEDGEMENTS}

We thank Drew Becker, Kassi Dallavis, Chris Eager, Lisa Hodges, Nate Raynor and Chris Schleffler for assistance with the field work. Funding was provided by the Office of Naval Research and the State of 

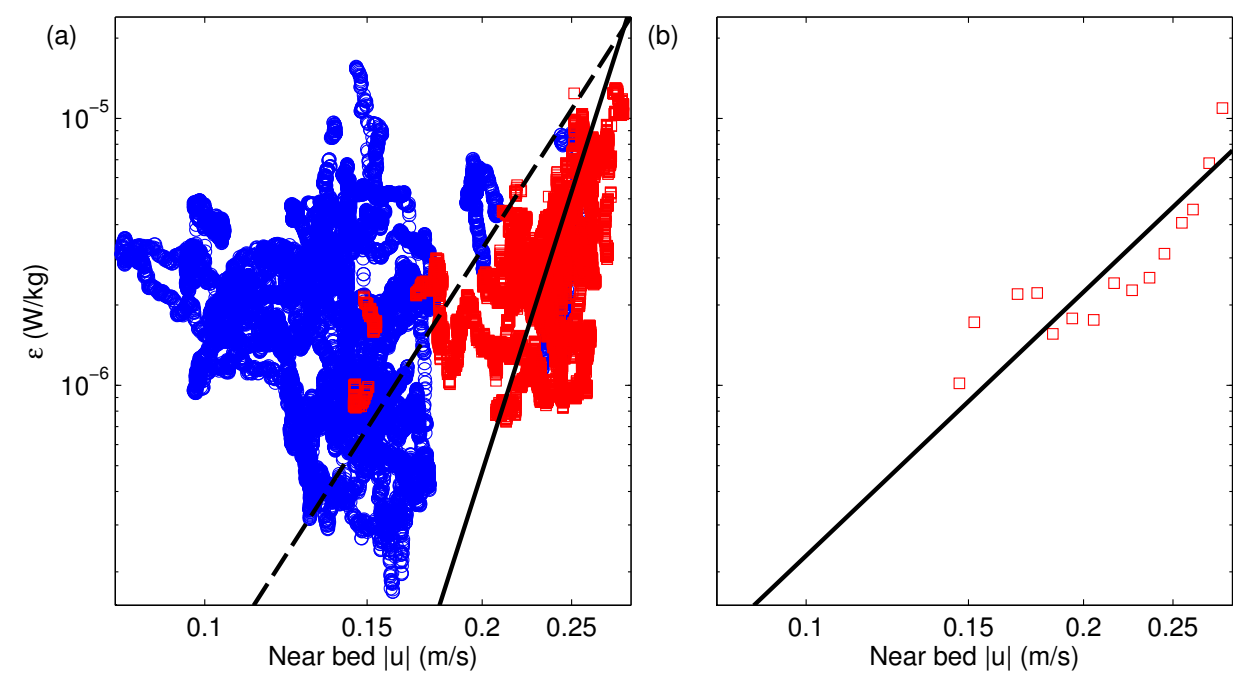

Figure 10: Near-bed TKE dissipation rates (measured $0.2 \mathrm{~m}$ above bottom). (a) Raw data (all points) and red squares show data after removal of channel crossings (times with backscatter $>140$ counts) and higher wave energy $\left(\sigma_{\mathbf{p}}^{2}+\sigma_{\mathbf{r}}^{2}>\mathbf{0 . 0 3 1}^{\circ 2}\right)$. The lines show fits to all data (dashed line, slope $=5.4$ ) and selected data (solid line, slope $=11$ ). (b) Data with low wave energy and low backscatter divided into $0.1 \mathrm{~m} \mathrm{~s}^{-1}$ velocity bins. Squares show mean of data in each bin, and the slope of the fit is 3.1. In all cases, the lines show the slope of the first EOF.

Washington.

\section{REFERENCES}

Austin, J. and S. Atkinson. 2004. The design and testing of small, low-cost GPS-tracked surface drifters, Estuaries 27, 1026-1029.

Grant, W.D. and O.S. Madsen. 1986. The continental shelf bottom boundary layer, Annual Reviews of Fluid Mechanics 18, 265-305.

Henderson, S.M. and J.C. Mullarney. 2012. Wave mixed, wind-generated near-surface shear observed over a tidal flat, Continental Shelf Research, doi: 10.1016/j.csr.2012.05.008.

Johnson, D., R. Stocker, R. Head, J. Imberger and C. Pattiaratchi. 2003. A compact low-cost GPS drifter for use in the oceanic nearshore zone, lakes and estuaries, Journal of Atmospheric and Oceanic Technology 20, 1880-1884.

Lhermitte, R. and R. Serafin. 1984. Pulse-to-pulse coherent Doppler sonar signal processing techniques. Journal of Atmospheric and Oceanic Technology, 1, 293-308.

Lohrmann, A., B. Hackett, and L.-P. Røed. 1990. High resolution measurements of turbulence, velocity and stress using a pulse-to-pulse coherent sonar, Journal of Atmospheric and Oceanic Technology, 7, 19-37.

Lohrmann, A. and S. Nylund 2008, Pulse Coherent Doppler Systems - How far can we push it? Proceedings of Current Measurement Technology Conference.

MacMahan, J., J. Brown and E. Thornton. 2009. Low-cost handheld global positioning system for measuring surf-zone currents, Journal of Coastal Research 25, 744-754, doi: 10.2112/08-1000.

Monin, A.S. and A.M. Yaglom. 1975. Statistical Fluid Mechanics: Mechanics of Turbulence, Volume 2, Dover, New York.

Mullarney, J.C. and S.M. Henderson. 2011. Hydraulically controlled front trapping on a tidal flat, Journal of Geophysical Research, 116, doi: 10.1029/2010JC006520

Mullarney, J.C. and S.M. Henderson. A low-cost drifter designed for use with a mounted Acoustic Doppler 
Profiler in shallow environments, manuscript in preparation.

Schmidt, W.E., B.T. Woodward, K.S. Millikan, R.T. Guza, B. Raubenheimer and S. Elgar. 2003. A GPSTracked Surf Zone Drifter, Journal of Atmospheric and Oceanic Technology 20, 1069-1075.

Simpson, J.E. 1997. Gravity currents in the environment and the laboratory, $2^{\text {nd }}$ edition, Cambridge University Press, Cambridge, UK.

Thomson, J. 2012. Wave breaking dissipation observed with SWIFT drifters, in press in Journal of Atmospheric and Oceanic Technology, doi: http://dx.doi.org/10.1175/JTECH-D-12-00018.1.

Wiles, P.J., T.P. Rippeth, J.H. Simpson and P.J. Hendricks. 2006. A novel technique for measuring the rate of turbulent dissipation in the marine environment, Geophysical Research Letters, 33, doi:10.1029/2006GL027050.

Zedel, L., A.E. Hay, R. Cabera and A. Lohrmann. 1996. Performance of a single beam pulse-to-pulse coherent Doppler profiler, IEEE Journal of Oceanic Engineering, 21, 290-297. 